\title{
Cardiac sympathetic dysfiunction in haemodialysed patients
}

Beata E. Chrapko', Grzegorz Staśkiewicz², Iwona J. Baranowicz-Gąszczyk ${ }^{3}$, Andrzej Książek ${ }^{3}$

${ }^{1}$ Chair and Department of Nuclear Medicine, Medical University of Lublin 2I Department of Radiology, Medical University of Lublin

${ }^{3}$ Chair and Department of Nephrology, Medical University of Lublin

[Received 2 I 2012; Accepted 16 I 2012]

\section{Abstract}

BACKGROUND: The aim of this study was to evaluate the cardiac sympathetic nervous system function in haemodialysed (HD), non-diabetic patients by iodine-123 meta-iodo-benzylguanidine $\left({ }^{123}|-m| B G\right)$.

MATERIALS AND METHODS: Planar scintigraphy of the chest was performed in $36 \mathrm{HD}$, male patients; 15 minutes and 4 hours post injection of $370 \mathrm{MBq}$ of ${ }^{123} \mathrm{l}-\mathrm{mIBG}$. The semiquantitative analysis of myocardial tracer uptake was expressed as routine heart to mediastinum $(\mathrm{H} / \mathrm{M})$ ratio: 15 minutes (early $\mathrm{H} / \mathrm{M}$ ) and 4 hour (late $\mathrm{H} / \mathrm{M}$ ) post administration as well as washout of the tracer from myocardium (WR). 24-hour Holter studies were recorded and heart rate variability (HRV) was evaluated. Patients were divided into two groups according to the $\mathrm{H} / \mathrm{M}$ value: group A patients with $\mathrm{H} / \mathrm{M}>1.8$ which has been accepted as a norm, and group $B$ patients with $\mathrm{H} / \mathrm{M}<1.8$.

RESULTS: In 21/36 patients $\mathrm{H} / \mathrm{M}$ ratio was below normal values. Significant differences between groups $A$ and $B$ were found among the following parameters: early $\mathrm{H} / \mathrm{M}$ and late $\mathrm{H} / \mathrm{M}$ ratios, WR and duration of haemodialysis therapy.

CONCLUSIONS: In patients with abnormal function of cardiac sympathetic nervous system, expressed by means of $\mathrm{H} / \mathrm{M}$ ratio below 1.8, duration of haemodialysis treatment was longer. Duration of HD appears to be an important factor influencing cardiac sympathetic nervous system.

Correspondence to: M.D., Ph.D. Beata E. Chrapko

Chair and Department of Nuclear Medicine,

Medical University of Lublin

ul. Jaczewskiego 8, 20-954 Lublin, Poland

Tel/fax: +48 817244339

e-mail: beata.chrapko@wp.pl
Key words: cardiac sympathetic nervous system, 123I-mIBG myocardial uptake, haemodialysis

Nuclear Med Rev 2012; 15, 1: 3-6

\section{Background}

In the Central Europe, the number of patients treated by renal replacement therapy has doubled every decade since 1980 [1]. In countries with low rate of renal transplant procedures, complications accompanying with long-term haemodialysis (HD) therapy are often observed. Among them, the cardiovascular complications are the leading cause of death, accounting at least $40 \%$ of deaths in end-stage renal disease (ESRD), $20 \%$ of which are sudden [2]. The hyperactivity of the cardiac sympathetic nervous system (CSNS) is observed in all stages of chronic renal disease (CRD) [3]. The CSNS function can be partly improved along with duration of dialysis [4] or after renal transplant [5]. But, despite the effectiveness of dialysis, circulating uremia-related toxins cause excitation of renal afferent nerves and activate CSNS [6]. Overhydration as well as accumulation of uremic toxins stimulate development of the left ventricular hypertrophy and dysfunction [2]. Nuclear medicine procedures are the only imaging modalities which enable in vivo visualization of global and regional cardiac CSNS functions. lodine-123 meta-iodo-benzylguanidine (123|-mIBG) SPECT depicts presynaptic uptake and storage of radiolabelled neurotransmitter $[7,8]$. It is well known, that dysfunction of CSNS is enhanced in diabetic patients, where diabetes mellitus (DM) is the most frequent cause of nephropathy $[9,10]$. However, the current report specifically evaluates the CSNS function in haemodialysed (HD), non-diabetic patients by iodine-123 meta-iodo-benzylguanidine ( ${ }^{123 \mid}$-mIBG).

\section{Materials and methods}

\section{Study population}

The study group comprised $36 \mathrm{HD}$ male patients (aged 29-79; $54.7 \pm 12.3$ years). All had HD sessions three times per week. Patients in poor general condition, unable to exercise, with DM, amyloidosis, dialysis-induced hypotension and neoplastic diseases were excluded from the study. The underlying cause of renal failure was chronic glomerulonephritis (18 patients) and other miscellaneous causes (18 patients). Patients who receive 
drugs that might affect cardiac sympathetic system (e.g. tricyclic antidepressants, sympathetic agents) were not included. An antihypertensive medications such as angiotensin converting enzyme inhibitors (ACEI) and angiotensin receptor blockers (ARB) in patients with hypertension were not withdrawn before ${ }^{123}$ I-mIBG scintigraphy, as suggested by Flotas et al. [11].

\section{3/-mIBG myocardial uptake}

Cardiac adrenergic system was evaluated on the day without $\mathrm{HD}$ sessions, at rest conditions, after IV injection of $370 \mathrm{MBq}$ ${ }^{123}|-m| B G$. The anterior planar images of the chest were performed on double-head, large field of view gamma camera Varicam (Elscint, Haifa, Israel), in two stages: after 15 minutes (early imaging) and after 4 hours (late imaging) post injection. In all studies 15\% energy window was set symmetrically at $159 \mathrm{keV}$ and low-energy high-resolution collimators were used. The images were collected on $128 \times 128$ matrix for 400 seconds. The ${ }^{123}$ - $-m$ IBG uptake was evaluated semiquantitatively by calculation of heart to mediastinum (H/M) ratio and myocardial washout rate (WR) according to EANM proposed standard [11] and to previously described methods [12]. To calculate $\mathrm{H} / \mathrm{M}$ ratio, two regions of interest (ROI) in anterior planar image were determined. The ROI of the heart $(\mathrm{H})$ was irregular, drawn over the entire outline of the heart and its size depending on the patient. The $\mathrm{ROI}$ of the mediastinum (M), was rectangle, $7 \times 7$ pixels in size, selected from the central superior mediastinum sector (Figure 1). The H/M was calculated from early and late imaging as follows:

$$
H / M=\frac{\text { mean count per pixel in heart R01 }(H)}{\text { Mean count per pixel in mediastinum } R 01(M)}
$$

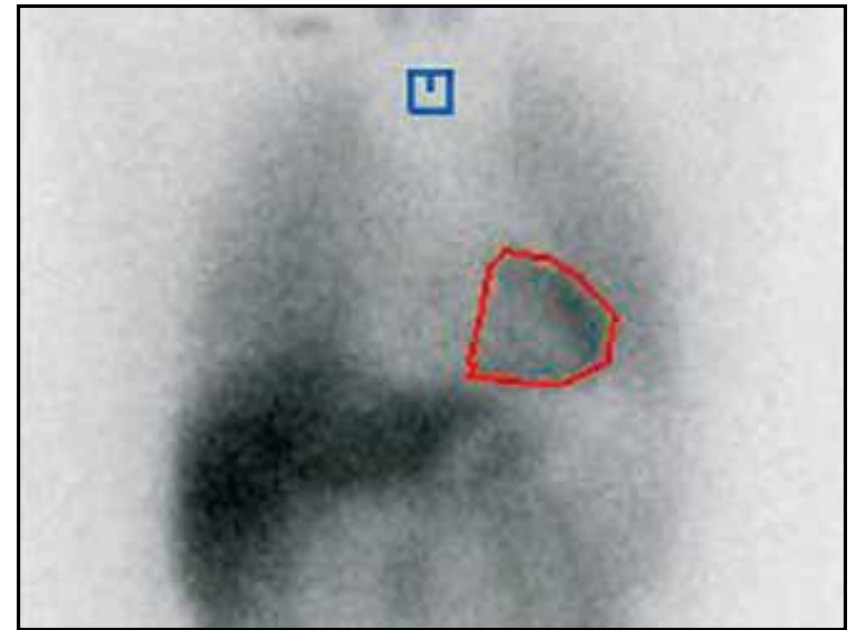

Figure 1. I-123 $\mathrm{mIBG}$ planar anterior projection of the thorax with examples of the heart $(\mathrm{H})$ and mediastinum $(\mathrm{M}) \mathrm{ROI}$

The myocardial WR was expressed as decreasing myocardial activity over time between early and late imaging, normalized to mediastinal activity [11] in the following manner:

$$
W R=\frac{\text { early imaging }(H-M)-\text { late imaging }(H-M)}{\text { early imaging }(H-M)} \times 100 \%
$$

Cardiac sympathetic nervous system was considered to be dysfunctional if $\mathrm{H} / \mathrm{M}$ ratio was below 1.8 [7, 10, 13]. According this value patients were divided into two groups: group A with normal function of CSNS and group B with impaired CSNS function (Table 1).

\begin{tabular}{|c|c|c|c|c|c|c|c|}
\hline \multirow[b]{2}{*}{ Parameters } & \multicolumn{3}{|c|}{ Group A; $n=15$} & \multicolumn{3}{|c|}{ Group B; $n=21$} & \multirow[b]{2}{*}{$P^{*}$} \\
\hline & Median & Minimum & Maximum & Median & Minimum & Maximum & \\
\hline Age (years) & 53 & 29 & 69 & 58 & 36 & 79 & NS \\
\hline mHD (months) & 12 & 4 & 108 & 53 & 7 & 132 & 0.03 \\
\hline Duration of hypertension (months) & 24 & 4 & 120 & 25 & 0 & 120 & NS \\
\hline Body mass index [kg/m²] & 23.3 & 15.9 & 30.7 & 24.3 & 18 & 36.2 & NS \\
\hline Calcium [mg/dl] & 8.8 & 8.1 & 10 & 8.7 & 7.84 & 10 & NS \\
\hline Phosphate [mg/dl] & 5.1 & 3.2 & 7.7 & 4.6 & 2.25 & 7.6 & NS \\
\hline Calcium-phosphate product & 45.6 & 30 & 62 & 44 & 16 & 66.12 & NS \\
\hline Parathyroid hormone [mg/dl] & 301 & 135 & 794 & 421 & 29 & 2670 & NS \\
\hline Haemoglobin [mg/dl] & 11.2 & 9.7 & 13.2 & 11.2 & 9.1 & 13.7 & NS \\
\hline Serum albumin [mg/dl] & 3.99 & 3.5 & 4.3 & 3.9 & 3.5 & 4.38 & NS \\
\hline $\mathrm{KtV}^{* *}$ & 1.48 & 1.27 & 1.76 & 1.47 & 1.03 & 1.89 & NS \\
\hline Early H/M & 1.93 & 1.8 & 2.44 & 1.74 & 1.37 & 1.76 & 0.01 \\
\hline Late $\mathrm{H} / \mathrm{M}$ & 1.89 & 1.8 & 2.24 & 1.59 & 1.18 & 1.70 & 0.001 \\
\hline Washout rate (WR) & 22.19 & 17.42 & 27.25 & 40.01 & 29.56 & 69.15 & 0.001 \\
\hline Heart rate variability [ms] (SDNN) & 108 & 79 & 160 & 85 & 53 & 201 & NS \\
\hline
\end{tabular}

Table 1. The comparison of studied parameters within group A and B

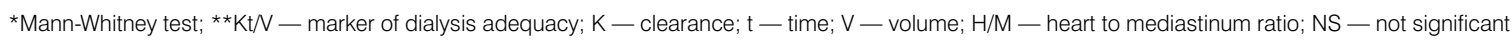




\section{Heart rate variability (HRV)}

In all patients a 24-hour ambulatory Holter recordings were performed using OXFORD CardioScan Suprima 12 system. For time-domain heart rate variability (HRV) measures, the standard deviation of normal-to-normal R-R intervals (SDNN) obtained during 24 hours were calculated.

\section{Statistical analysis}

All calculations were expressed as median, minimal and maximal values. The differences between the study groups were assessed with Mann-Whitney test; $p$ value $<0.05$ was considered to indicate statistical significance. Data was analyzed using SPSS 16.0 (SPSS Inc., Chicago, IL) statistical software.

\section{Ethics}

Each of the patients signed an informed consent form. The study protocol and informed consent forms were approved by The Bioethical Council, Medical University of Lublin, Poland. The test was well tolerated by all of the patients.

\section{Results}

The semiquantitative evaluation of ${ }^{123}$ - $-m \mid B G$ myocardial uptake revealed abnormal (lower than 1.8) value of early and late $\mathrm{H} / \mathrm{M}$ ratio in 21 (58\%) out of 36 patients (B group). Normal values were found in $15(42 \%)$ of 36 patients (group A). There were significant differences between group $A$ and $B$ among this indices. The values of myocardial WR were significantly higher in group B compare with A. Moreover the duration of haemodialysis therapy in patients in group B was significantly longer than in group $A$. The heart rate variability, expressed by SDNN was not significantly different between groups $\mathrm{A}$ and $\mathrm{B}$ (Table 1).

\section{Discussion and conclusions}

The uremic changes in the circulatory system leads to the heart failure, the main cause of death in CRD. Dysfunction of CSNS largely influences presentation of cardiovascular complications in HD patients. The major cardiac events (MCE) often occur within the first year of HD [14-16]. Nevertheless, HD patients are often undiagnosed with abnormal cardiac sympathetic nervous system function.

In current study, patients were divided into two groups according to the $\mathrm{H} / \mathrm{M}$ value, where 1.8 was considered as a normal, based on previous studies performed in similar method [10, 13, 17]. Patients with $D M$ and amyloidosis were excluded from our study, because of evident influence on CSNS [9, 13, 18, 19-21]. The semiquantified evaluation of ${ }^{123} \mathrm{l}-\mathrm{mIBG}$ myocardial uptake was expressed as early and late $\mathrm{H} / \mathrm{M}$ ratios as well as WR. The early $\mathrm{H} / \mathrm{M}$ ratio reflects the integrity of pre-synaptic nerve endings and neuronal uptake of neurotransmitters, whereas the late $\mathrm{H} / \mathrm{M}$ ratio combines information on neuronal function from uptake to release through the storage vesicle at the nerve endings. This functionality were impaired in $58 \%$ of studied patients. The value of both: early and late $\mathrm{H} / \mathrm{M}$ ratios in group $\mathrm{B}$ were significantly lower than in group A. But, values of both early and late $\mathrm{H} / \mathrm{M}$ ratios in group $\mathrm{B}$ were not as low as 1.2, which value indicated patients with high risk of cardiovascular death [22]. Myocardial ${ }^{123} \mathrm{I}-\mathrm{mIBG}$ WR is an index of the degree of sympathetic tone. The increased CSNS activity manifests as high myocardial WR and low late uptake of ${ }^{123} \mathrm{l}-\mathrm{mIBG}$. It is considered as the poor prognostic factor of major cardiac events [23, 24]. The normal WR values range from $20 \% \pm 10 \%$ [25]. In our patients this index exceeded normal value only in group $B$, whereas in group $A$ the maximal value came to 27.25. According to Kioka et al. the value of myocardial WR higher or equal than $27 \%$ is the only independent predictor of sudden cardiac death (SCD) [26]. Our main fining is that, in patients with abnormal $\mathrm{H} / \mathrm{M}$ ratio, which reflects sympathetic function, the duration of haemodialysis is significantly longer in comparison with patients with normal $\mathrm{H} / \mathrm{M}$ ratio.

Decreased HRV, reflected by low values of SDNN in 24-hour Holter monitoring (especially below $50 \mathrm{~ms}$ ) identifies patients at an increased risk for $S C D$, which is also proven in the population of $\mathrm{HD}$ patients $[27,28]$. In group $\mathrm{B}$, the minimal value of SDNN was close to 50 , but there is no significant different in $\mathrm{HRV}$ between groups A and B, similarly to other authors [13].

The semiquantitative assessment of ${ }^{123}$ - - IIBG myocardial uptake is an important tool in evaluation of the cardiac sympathetic nervous system function. This function may deteriorate with duration of haemodialysis. It has been found that, in patients with abnormal function of cardiac sympathetic nervous system, expressed by means of lower than 1.8 H/M ratio, duration of haemodialysis treatment was longer. It brings us to conclusion that duration of haemodialysis treatment appears to be an important factor influencing cardiac sympathetic nervous system. The H/M ratios and WR are more sensitive indices of CSNS damage than heart rate variability.

Conflicts of interest - none

\section{Acknowledgments}

This study was supported by the Polish Ministry of Science and Higher Education (NN402 084034).

\section{References}

1. Rutkowski B. Highlights of the epidemiology of renal replacement therapy in Central and Eastern Europe. Nephrol Dial Transplant 2006; 21: 4-10.

2. McMahon LP. Hemodynamic cardiovascular risk factors in chronic kidney disease: what are the effects of intervention? Semin Dial 2003; 16: 128-139.

3. Masuo K, Lambert GW, Esler MD, Rakugi H, Ogihara T, Schlaich MP. The role of sympathetic nervous activity in renal injury and end-stage renal disease. Hypertens Res 2010; 33: 521-528.

4. Laaksonen S, Voipio-Pulkki L, Erkinjuntti M, Asola M, Falack B. Does dialysis therapy improve autonomic and peripheral nervous system abnormalities in chronic uraemia? J Int Med 2000; 248: 21-26.

5. Kurata C, Uehara A, Ishikawa A. Improvement of cardiac sympathetic innervation by renal transplantation. Journal of Nuclear Medicine 2004; 45: 1114-1120.

6. Recordati G, Moss NG, Genovesi S et al. Renal chemoreceptors. J Auton Nervous System 1981; 3: 237-251.

7. Carrio I. Cardiac neurotransmission imaging. J Nucl Med 2001; 42 : 1062-1076.

8. Henneman MM, Bengel FM, van der Wall EE, Knuuti J, Bax JJ. Cardiac neuronal imaging: Application in the evaluation of cardiac disease. J Nucl Cardiol 2008; 15: 442-455. 
9. Sato M, Horigome I, Chiba S et al. Autonomic insufficiency as a factor contributing to dialysis-induced hypotension. Nephrol Dial Transplantat 2001; 16: 1657-1662.

10. Somsen GA, Verberne HJ, Fleury E, Righetti A. Normal values and within-subject variability of cardiac I-123 MIBG scintigraphy in healthy individuals: Implications for clinical studies. J Nucl Cardiol 2004; 11: 126-133.

11. Flotas A, Carrio I, Agostini D et al. Proposal for standardization of 123-I-metaiodobenzylguanidine (MIBG) cardiac sympathetic imaging by the EANM Cardiovascular Committee and the European Council of Nuclear Cardiology. Eur J Nucl Med Mol Imaging 2010; 37: 1802-1812.

12. Chrapko BE, Jaroszyński AJ, Głowniak A, Bednarek-Skublewska A, Załuska W, Książek A. lodine-123 metaiodobenzylguanidine myocardial imaging in haemodialysed patients asymptomatic for coronary artery disease: a preliminary report. Nucl Med Commun 2011; 32: 515-521.

13. Scholte AJHA, Schuijf JD, Delgado $V$ et al. Cardiac autonomic neuropathy in patients with diabetes and no symptoms of coronary artery disease: comparison of 1231-metaiodobenzylguanidine myocardial scintigraphy and heart rate variability. Eur J Nucl Med Mol Imaging 2010; 37: 1698-1705.

14. Goldsmith DJA, Covic A. Coronary artery disease in uremia: etiology, diagnosis and therapy. Kidney International 2001; 60: 2059-2078.

15. Hase $\mathrm{H}$, Joki $\mathrm{N}$, Ishikawa $\mathrm{H}$ et al. Prognostic value of stress myocardial perfusion imaging using adenosine triphosphate at the beginning of haemodialysis treatment in patients with end-stage renal disease. Nephrol Dial Transplant 2004; 19: 1161-1167.

16. Hatta T, Nishimura S, Nishimura T. Prognostic risk stratification of myocardial ischaemia evaluated by gated myocardial perfusion SPECT in patients with chronic kidney disease. Eur J Nucl Med Mol Imaging 2009; 36: 1835-1841.

17. Agostini D, Verberne HJ, Burchert W et al. I-123-mIBG myocardial imaging for assessment of risk for a major cardiac event in heart failure patients: insights from a retrospective European multicenter study. Eur J Nucl Med Mol Imaging 2008; 35: 535-546.
18. Scott LA, Kench PL. Cardiac autonomic neuropathy in the diabetic patients: does 123I-MIBG imaging have a role to play in early diagnosis? J Nucl Med Technol 2004; 32: 66-71.

19. Nagamachi S, Fujita S, Nishi R et al. Prognostic value of cardiac l-123 metaiodobenzylguanidine imaging in patients with non-insulin-dependent diabetes mellitus. J Nucl Cardiol 2006; 13: 34-42.

20. Tanaka M, Hongo M, Kinoshita $O$ et al. lodine-123 metaiodobenzylguanidine scintigraphy assessment of myocardial sympathetic innervation in patients with familiar amyloid polyneuropathy. J Am Coll Cardiol 1997; 29: 168-174.

21. Nakata T, Shimamoto K, Yonekura S et al. Cardiac sympathetic denervation in transthyretin-related familiar amyloidotic polyneuropathy: detection with iodine-123-MIBG. J Nucl Med 1995; 36: 1040-1042.

22. Merlet P, Benvenuti C, Moyse D et al. Prognostic value of MIBG imaging in idiopatic dilated cardiomyopathy. J Nucl Med 1999; 40: 917-923.

23. Agostini D, Carrio I, Verberne HJ. How to use myocardial 123I-MIBG scintigraphy in chronic heart failure. Eur J Nucl Med Mol Imaging 2009; 36: 555-559.

24. Akutsu Y, Kaneko K, Kodama $Y$ et al. Cardiac sympathetic nerve abnormality predicts ventricular tachyarrhythmic events in patients without conventional risk of sudden death. Eur J Nucl Med Mol Imaging 2008; 35: 2066-2073.

25. Flotats A., Carrió I. Cardiac neurotransmission SPECT imaging. J Nucl Cardiol 2004; 11: 587-602.

26. Kioka H, Yamada T, Mine T et al. Prediction of sudden cardiac death by using cardiac iodine-123 metaiodobenzylguanidine imaging in patients with mild to moderate chronic heart failure. Heart 2007; 93: 1213-1218.

27. Ranpuria R, Hall M, Chan CT, Unruh M. Heart rate variability (HRV) in kidney failure: measurement and consequences of reduced HRV. Nephrol Dial Transplant 2008; 23: 444-449.

28. Meier P, Vogt P, Blanc E. Ventricular arrhythmias and sudden cardiac death in end-stage renal disease patients on chronic heamodialysis. Nephron 2001; 87: 199-214. 